УДК 372.8

\title{
ОРГАНИЗАЦИЯ ПРОЕКТНОЙ ДЕЯТЕЛЬНОСТИ НА УРОКАХ АНГЛИЙСКОГО ЯЗЫКА НА ОСНОВЕ МЕЖПРЕДМЕТНЫХ СВЯЗЕЙ
}

\author{
Булахова Ирина Дмитриевна \\ ФГБОУ ВО «Магнитогорский государственный \\ технический университет им. Г.И. Носова»
}

\begin{abstract}
Аннотация: В статье рассматривается возможность использования проектной методики на уроках английского языка. Проектный метод является достаточно важным инструментом развития интеллектуальных способностей обучающихся, а также повышения эффективности процесса обучения. Актуальность овладения учителями основ проектирования обусловлена тем, что проектная деятельность имеет широкую область применения на всех уровнях организации системы образования, в том числе при изучении английского языка. В статье описаны несколько видов проектной деятельности и приводится их краткая характеристика. Кроме того, приведён пример поэтапного выполнения проекта.
\end{abstract}

Ключевые слова: проектный метод, образование, английский язык, история, учитель.

\section{ORGANIZATION OF PROJECT ACTIVITIES IN ENGLISH CLASSES BASED ON INTERDISCIPLINARY CONNECTIONS}

\section{Bulakhova Irina Dmitrievna}

\begin{abstract}
The article discusses the possibility of using the project methodology in English lessons. The project method is quite an important tool for developing intellectual abilities of learners, as well as increasing the effectiveness of the learning process. The relevance of mastering the basics of designing projects by teachers is due to the fact that project activities have a wide range of applications at all levels of the organization of the education system, including the study of English. The article describes several types of project activities and provides their brief description. In addition, a phased implementation example of the project is included in the article.
\end{abstract}

Key words: project method, education, English language, history, teacher. 
В настоящее время образование в России перешло на Федеральный государственный образовательный стандарт нового поколения [1]. Данный документ определяет задачи современного образования в нашей стране. Основной задачей является воспитание личности, способной находить нестандартные решения, мыслить самостоятельно. Важной задачей является воспитать человека, который готов учиться новому на протяжении всей своей жизни. Все эти навыки формируются со школьной скамьи. Обучение должно проходить таким образом, чтобы по окончании школы выпускники стремились творчески развиваться и достигать поставленных целей, гибко реагировать на изменения жизненной ситуации.

Российская система образования переходит от традиционного обучения в виде формирования знаний, умений и навыков к формированию личностей с новым типом мышления, инициативных, творческих личностей, смелых в принятии решений, практичных. Таким образом, намечается отход от традиционной системы обучения, ориентированной на «усвоение всей суммы знаний, которое выработало человечество», к обучению, в процессе которого формируется человек, способный к самоопределению и самореализации. Вышеуказанные изменения приводят к необходимости изменения методик образования.

Одним из наиболее перспективных методов является метод проектов комплексный метод обучения, позволяющий строить учебный процесс исходя из интересов студентов, дающий возможность студенту проявить самостоятельность в планировании, организации и контроле своей учебнопознавательной деятельности. Проектная деятельность ориентирована на самостоятельную деятельность студентов - индивидуальную, парную, групповую.

Метод проектов широко известен в мировой педагогической практике. Впервые он был описан в книге «Метод проектов» в 1918 г. американским психологом и педагогом Вильямом Килпатриком [2].

В нашей стране метод одно время довольно широко стал применяться в школах по личной инициативе Н.К. Крупской. Однако по разным причинам метод проектов практически перестал использоваться в нашей стране в дальнейшем.

В 30-50 годы XX века наша страна находилась в тяжелом экономическом положении, a после Великой Отечественной Войны отмечалась физическая нехватка учителей, многие дети военного времени 
были оторваны от учебного процесса. Перед страной стояла задача в кратчайшие сроки не просто достигнуть довоенного уровня обучения, но и догнать передовые страны. Проектный метод в данных условиях вряд ли выполнил бы поставленные государством задачи. В настоящее время положения положение коренным образом изменилось, метод проектов органично вписался в государственную политику.

В зарубежных же странах метод проектов продолжал широко использоваться в школьной и университетской практике все эти годы, развиваясь и совершенствуя свою процессуальную, технологическую суть. Так в чём же притягательная сила метода проектов, который длительное время не покидает школу, высшие учебные заведения, модернизируя свою концепцию, время от времени, сообразуясь скорее с запросами общества, чем с чистой наукой. Новая волна распространения метода проектов, свидетелями которой мы являемся, связана с философией образования и психологией мышления Дж. Дьюи и его последователей, с теорией деятельности, разработанной советскими психологами, личностно ориентированным подходом.

Обратимся к основным концептуальным положениям Дж. Дьюи, его последователей и к основным положениям теории деятельности. Дж. Дьюи предлагал строить обучение на активной основе, через целесообразную деятельность ученика, сообразуясь вместе с тем с его интересами именно в этом знании. Он считал особенно важным стимулировать в детях их личную заинтересованность в приобретаемых знаниях, которые могут и должны пригодиться им в жизни. А.Н. Леонтьев специально подчёркивал, что «деятельность - это не реакция и не совокупность реакций, а система, имеющая строение, свои внутренние переходы и превращения, своё развитие» $[3$, c.57].

Цель метода проектов - направить познавательную деятельность учеников на определенный и запланированный результат, который получается при решении той или иной задачи.

Данная цель может быть решена при совокупности воспитательнообразовательных задач:

- развитие комплексных умений и навыков: исследовательских, рефлексивных, самооценочных;

- развитие познавательных интересов детей через создание проблемной ситуации; 
- формирование активной, самостоятельной и инициативной позиции детей.

Концептуальные положения технологии метода проектов, разработанные Дж. Дьюи, раскрывают логику метода проекта. Суть идей ученого заключается в следующем:

- pебенок в онтогенезе повторяет путь человечества в познании;

- усвоение знаний есть спонтанный, неуправляемый процесс;

- ребенок усваивает материал, не просто слушая или воспринимая органами чувств, а как результат удовлетворения возникшей у него потребности в знаниях, являясь активным субъектом своего обучения.

Можно обозначить следующие типы проектов: исследовательские, творческие, ролево-игровые, информационные, практико-ориентированные.

Рассмотрим классификацию проектов по доминирующему методу, предложенную Полат Е.С. [4, с.193]:

1. Исследовательские проекты - эти проекты должны быть с продуманной структурой, целями, актуальностью предмета исследования, источниками информации, результатами. Они приближенны к научному исследованию. А также студенты должны соответствовать уровню языковой подготовки на определенном этапе обучения.

2. Творческие проекты - эти проекты не имеют проработанной структуры и должны оформляться соответствующе: видеофильм, сочинение, газетная статья, ролевая игра и т.д.).

3. Ролево-игровые проекты - эти проекты с открытой структурой, в которых студенты принимают на себя роли, обусловленные содержанием проекта и особенностью решаемой проблемы (литературные персонажи, выдуманные герои и т.д.). Результаты таких проектов могут намечаться в начале проекта, а могут проявляться лишь к его окончанию.

4. Информационные проекты - эти проекты изначально направлены на сбор информации о каком-либо объекте или явлении. Структура такого проекта может быть обозначена следующим образом: цель проекта, предмет информационного поиска источники информации. Такие проекты часто интегрируются с исследовательскими проектами и становятся их органичной частью, модулем.

5. Практико-ориентированные проекты - эти проекты различаются четко обозначенным результатом деятельности студентов проекта, который обязательно ориентирован на социальные интересы самих участников. 
Кроме того, проекты делятся по комплексности и характеру контактов:

1. Монопроекты - эти проекты проводятся в рамках одного учебного предмета, из которого выбираются наиболее сложные темы с социальной, исторической или страноведческой тематикой. Как правило, работа над такими проектами предусматривает применение знаний на других областей.

2. Межпредметные проекты - эти проекты выполняются во внеурочное время и могут затрагивать несколько предметов, чтобы решить какую-либо задачу, значимую для всех участников проекта. В таком проекте могут принимать участие много творческих групп, имеющих определенные исследовательские задания.

3. Проекты с открытой, явной координацией - в этих проектах принимает участие непосредственно координатор проекта, ненавязчиво направляя работу обучающихся, организуя в случае необходимости отдельные этапы проекта, деятельность отдельных его участников, например, если нужно договориться о встрече в каком-то официальном заведении, провести анкетирование, взять интервью.

4. Проекты со скрытой координацией - в этих проектах координатор выступает как полноправный участник проекта. Примером их могут служить известные телекоммуникационные проекты. Что касается характера контактов, то проекты могут быть внутренними или региональными, международными.

5. Внутренние или региональные - это проекты, которые организуются внутри одного учебного заведения, на уроках по одному предмету, либо между учебными заведениями, внутри региона, одной страны.

6. Международные проекты - в этих проектах участвуют представители разных стран. Они представляют исключительный интерес, поскольку для их реализации требуются средства информационных технологий.

Однако на практике чаще всего приходится иметь дело со смешанными типами проектов. Поэтому при разработке проекта следует иметь в виду признаки и характерные особенности каждого из них.

По нашему мнению, одним из наиболее эффективных видов методов проектов являются межпредметные проекты. В настоящее время большое внимание уделяется изучению истории и иностранного языка, рассматривается вопрос о введении данных предметов в список обязательных предметов ЕГЭ. 
Отметим, что проекты, связанные с изучением истории, позволяют их участникам исследовать самые разнообразные исторические проблемы; прогнозировать развитие событий политических, социальных, анализировать какие-то исторические события, факты. Языковые проекты чрезвычайно популярны, поскольку они касаются проблемы изучения иностранных языков, что особенно актуально в настоящее время и вызывает живейший интерес участников проектов. Объединение изучения этих двух направлений в виде межпредметного проекта является перспективным и соответствующим духу Федерального государственного образовательного стандарта.

Цели учебного проекта:

1. знакомство учащихся с интересными историческими фактами на английском языке; изучение деятельности исторических личностей англоязычных стран в первоисточнике;

2. развитие умений учащихся самостоятельно добывать информацию из книг, Интернета и практически использовать полученные знания; многие исторические факты из истории зарубежных стран более подробно описаны на английском языке, поэтому при выполнении поиска по заданной теме ученик невольно прикоснется к оригинальной англоязычной трактовке событий и переведет их на русский язык для понимания материала;

3. организация продуктивной, творческой деятельности каждого учащегося в процессе выполнение проектного задания (для выполнения данных заданий возможны театральные (дискуссионные) мероприятия, выполняемые учениками);

4. умение анализировать материалы путем споров, обсуждений и доказательств практического характера; исторические события всегда являют собой противоречия между различными группами людей и многовариантны в виде вероятного будущего. Обсуждение реконструкций иных вариантов будущего (в том числе англоязычных стран) на английском языке вызовет интерес учащихся к изучению новых слов и увеличению словарного запаса;

5. приобретение знаний, умений, навыков по истории и английскому языку; после выполнения данных проектов учащиеся не только более глубоко погрузятся в историческую атмосферу, но и более прочно овладеют навыками общения на английском языке;

6. развитие цифровых навыков обучающихся, умения пользоваться цифровыми технологиями для получения практических результатов, работать 
в онлайн приложениях, чтобы создавать цифровой контент и взаимодействовать с участниками команды.

Рассмотрим пример данного метода при изучении английского языка и истории.

Первый этап - подготовительный.

На этом этапе раздел исследования должен быть поделен на отдельные вопросы; каждая группа учащихся должна выбрать вопрос раздела истории в соответствии со своими интересами.

Например, будут предложены следующие вопросы:

- Причины вступления России в Первую Мировую Войну. Цели и задачи стран, принявших участие в конфликте.

- Наступление фронта под руководством генерала Брусилова А.А. в 1916 г.

- Ситуация в России накануне свержения императора Николая II. Цели и задачи участников свержения.

Второй этап - исследовательский.

Учащиеся в процессе исследования консультируются с учителями предметниками в выборе источников сбора и анализа информации и её перевода, идёт процесс сбора и уточнения.

Выявляются альтернативные точки зрения различных историков, изучается возможность защиты этих точек зрения в виде дебатов, решаются проблемы, возникшие в ходе выполнения проекта («мозговой штурм») и выбирается оптимальная точка зрения, доказанная в различных исторических источниках, в том числе обязательно иноязычных.

Третий этап - планирование работы.

Особенностью группового проекта на данном этапе является необходимость проводить общие консультации, целью которых является выработка единых требования к содержанию и оформлению индивидуальных заданий.

Четвёртый этап - практический.

Учащиеся выполняют проект согласно утверждённым требованиям. В связи с тем, что все ученики имеют различный уровень иностранного языка, желательно, чтобы в переводе информации и подготовке к защите проекта принимали все ученики вне зависимости от их уровня. Данный этап включает изучение новых иностранных слов и выражений, которые являются типичными в иноязычных исторических источниках. 
Пятый этап - защита проекта.

Данный этап представляет собой общий интегрированный урок, на котором учащиеся представляют разработанные проекты, обосновывают сделанные выводы и дают оценку приведённым фактам. На данный урок приглашаются учителя-историки и учителя иностранного языка. Оценка результатов работы происходит на этапе защиты проекта.

Этап оценки предусматривает рассмотрение всех аспектов проекта: насколько были реализованы поставленные цели, правильно ли использованы данные, корректно ли применены иноязычные выражения.

Хочется отметить большой позитивный и кумулятивный эффект от изучения истории и иностранных языков в школе и формирование компетенции культурно-досуговой деятельности, а также межвозрастную интеграцию и вовлечение большого количества учащихся в совместную проектную деятельность.

Таким образом, в данной статье был рассмотрен метод проектов и его использование в учебном процессе. При реализации метода проектов в образовательный процесс широко включаются приемы, основанные на создании проблемных ситуаций, стимулировании активной познавательной деятельности воспитанников, предполагающей поиск и решение сложных вопросов, требующих актуализации знаний, аналитической деятельности, умения видеть в отдельных фактах проявления закономерностей, сущностных характеристик явления.

\section{Список литературы}

1. Федеральный государственный образовательный стандарт начального общего образования/ Министерство образования и науки Российской Федерации. - М.: Просвещение, 2010.

2. Kilpatrick William Heard. The Project Method / William Heard Kilpatrick // Teachers College Record. - 1918

3. Леонтьев А.Н. Деятельность. Сознание. Личность. - М.: Смысл, Академия, 2005.

4. Полат Е.С. Современные педагогические и информационные технологии в системе образования. - М.: изд. центр «Академия», 2010. 